\title{
EDITORIAL
}

\section{Living with pulmonary hypertension: quality not just quantity}

\section{R. Condliffe}

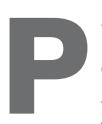
ulmonary arterial hypertension $(\mathrm{PAH})$ is a rare disease characterised by progressive right heart failure and premature death with a median survival prior to the availability of effective treatments of $<3 \mathrm{yrs}[1,2]$. There has been significant progress in its management over the last two decades with the introduction of three classes of targeted therapies: prostanoids, endothelin-1 receptor antagonists (ERAs) and phosphodiesterase-5 inhibitors [3]. A number of randomised controlled trials (RCTs) have demonstrated the efficacy of these drugs in terms of exercise capacity, functional class and pulmonary haemodynamics [4-11]. Observational studies have suggested improved survival when compared with historical series [12-14] and a recent meta-analysis of RCTs has confirmed a significant survival benefit associated with targeted therapies [15]. These therapies, however, have potentially significant side-effects related to continuous intravenous or subcutaneous infusion, frequent nebulisation or the requirement for close biochemical monitoring. In this context, the demonstration of therapy-related improvements in healthrelated quality of life (HRQoL), and not just in relatively modest improvements in exercise capacity or pulmonary haemodynamics, is of great importance to patients, prescribers and providers alike.

The majority of RCTs in PAH have assessed HRQoL as a secondary outcome using either generic tools, such as the Short Form (SF)-36 health survey, or measures validated in cardiac disease, such as the Minnesota Living with Heart Failure Questionnaire (LHFQ) [16, 17]. The results have been inconsistent, with some studies demonstrating significant improvement in HRQoL in at least some domains $[4,6,8,9,18,19]$ while others have failed to demonstrate any significant effect on HRQoL at all $[11,20]$. There have been relatively few studies specifically assessing HRQoL in PAH. Initial studies examined the nature and level of HRQoL impairment and observed significant impairment across multiple domains [21, 22]. Interestingly, HRQoL correlated with exercise capacity as measured by the 6-min walk distance (6MWD) and World Health Organization (WHO) functional class, but not pulmonary haemodynamics [22]. Although TAICHMAN et al. [22] demonstrated impairment in HRQoL as assessed by the St George's Respiratory Questionnaire (SGRQ; a pulmonaryspecific tool) and SF-36, no direct comparison between these generic and pulmonary-specific tools was made. Subsequent

CORRESPONDENCE: R. Condliffe, Pulmonary Vascular Disease Unit, Royal Hallamshire Hospital, Sheffield, S10 2JF, UK. E-mail: robin.condliffe@sth.nhs.uk studies assessed the change in HRQoL over time. CENEDESE et al. [23] found the LHFQ to be moderately responsive to therapy and also predictive of event-free survival. The generic SF-36 has been compared with the cardiac-specific LHFQ in two previous studies, which once again demonstrated significant associations with changes in 6MWD and WHO functional class [24, 25]. In recognition of the need for a PAH-specific HRQoL assessment tool, McKenNa et al. [26] and GomBerG-MaitLand et al. [27] constructed the Cambridge Pulmonary Hypertension Outcome Review (CAMPHOR), which has since been validated in a US cohort. The effect of bosentan, an ERA, on HRQoL was subsequently assessed in 55 patients; interestingly, the CAMPHOR score was found to be more sensitive to changes in HRQoL than the WHO functional class [28].

With the availability of generic, pulmonary-specific, cardiacspecific and PAH-specific HRQoL assessment measures, it is therefore high time that the most appropriate and responsive tool for use in future PAH trials is identified. The study by CHEN et al. [29] in the current issue of the European Respiratory Journal goes some way towards this. In their study, they enrolled 128 consecutive PAH patients and prospectively compared three main assessment tools: the generic SF-36, the cardiac-specific LHFQ and the pulmonary-specific 20-item Airways Questionnaire (AQ-20), which had previously been developed by the SGRQ investigators as a similar but less onerous test [30]. They also compared the PAH-specific CAMPHOR score, although due to the timing of the study, this was only available for a minority of the whole cohort. Some important findings were observed. First, the LHFQ correlated strongly with the AQ-20 while both tools showed convergent validity in correlating with the SF-36. Secondly, scores for the LHFQ and AQ-20 were non-normally distributed with evidence of a "ceiling effect" (i.e. a proportion of patients had the best possible score at baseline). Thirdly, although the three main HRQoL tools discriminated well between patients based on WHO functional class and Borg Dyspnoea Index (BDI), the LHFQ and AQ-20 failed to discriminate between patients in the lower two quartiles of $6 \mathrm{MWD}$, a possible "floor effect". In addition, although all three main HRQoL measures were responsive to change in WHO functional class, $6 \mathrm{MWD}$ and BDI, over time, they were less sensitive to worsening than to improvement. Overall, the AQ-20 was the least responsive test while the LHFQ was the most responsive. Also, there was some suggestion that the LHFQ was superior to the AQ-20 in predicting both the physical component score of the SF-36 and the CAMPHOR score in the small subset of patients with CAMPHOR results at follow-up. Finally, estimates of clinically 
meaningful change for each tool were derived using two separate methods; these should be of significant value when interpreting the clinical significance of changes in HRQoL in future trials.

So how much further forward do these findings take us? PAH is a condition affecting the interface between the pulmonary and cardiovascular systems. The present study suggests that in a cohort of PAH patients typical of those enrolled in RCTs, both cardiac- and pulmonary-specific tools are indeed valid methods of assessing HRQoL. There is also evidence to suggest that the cardiac-specific LHFQ is the superior of the two system-specific measures. The case for superiority of systemspecific over more generic HRQoL measures is, however, not yet proven. Two important avenues of research into PAHassociated HRQoL follow on from this point. First, to more confidently identify the optimal HRQoL measure for use in PAH trials, the SF-36 and LHFQ measures must now be compared with the disease-specific CAMPHOR in a large prospective cohort. Secondly, the optimal HRQoL measure for subgroups of $\mathrm{PAH}$ in which comorbidities may also negatively impact on HRQoL, such as systemic sclerosis-associated PAH (in which HRQoL is significantly lower than even in idiopathic $\mathrm{PAH}[22])$, needs specific investigation.

\section{STATEMENT OF INTEREST}

A statement of interest for R. Condliffe can be found at www.erj. ersjournals.com/site/misc/statements.xhtml

\section{REFERENCES}

1 D'Alonzo GE, Barst RJ, Ayres SM, et al. Survival in patients with primary pulmonary hypertension. Results from a national prospective registry. Ann Intern Med 1991; 115: 343-349.

2 Simonneau G, Robbins IM, Beghetti M, et al. Updated clinical classification of pulmonary hypertension. J Am Coll Cardiol 2009; 54: Suppl. 1, S43-S54.

3 Galie N, Hoeper MM, Humbert M, et al. Guidelines for the diagnosis and treatment of pulmonary hypertension. Eur Respir $J$ 2009; 34: 1219-1263.

4 Barst RJ, Rubin LJ, Long WA, et al. A comparison of continuous intravenous epoprostenol (prostacyclin) with conventional therapy for primary pulmonary hypertension. The Primary Pulmonary Hypertension Study Group. N Engl J Med 1996; 334: 296-302.

5 Rubin LJ, Badesch DB, Barst RJ, et al. Bosentan therapy for pulmonary arterial hypertension. N Engl J Med 2002; 346: 896-903.

6 Simonneau G, Barst RJ, Galie N, et al. Continuous subcutaneous infusion of treprostinil, a prostacyclin analogue, in patients with pulmonary arterial hypertension: a double-blind, randomized, placebo-controlled trial. Am J Respir Crit Care Med 2002; 165: 800-804.

7 Olschewski H, Simonneau G, Galie N, et al. Inhaled iloprost for severe pulmonary hypertension. N Engl J Med 2002; 347: 322-329.

8 Galie N, Ghofrani HA, Torbicki A, et al. Sildenafil citrate therapy for pulmonary arterial hypertension. N Engl J Med 2005; 353: 2148-2157.

9 Galie N, Badesch D, Oudiz R, et al. Ambrisentan therapy for pulmonary arterial hypertension. J Am Coll Cardiol 2005; 46: 529-535.

10 Galie N, Brundage BH, Ghofrani HA, et al. Tadalafil therapy for pulmonary arterial hypertension. Circulation 2009; 119: 2894-2903.
11 Barst RJ, Langleben D, Frost A, et al. Sitaxsentan therapy for pulmonary arterial hypertension. Am J Respir Crit Care Med 2004; 169: 441-447.

12 Sitbon $\mathrm{O}$, Humbert $\mathrm{M}$, Nunes $\mathrm{H}$, et al. Long-term intravenous epoprostenol infusion in primary pulmonary hypertension: prognostic factors and survival. J Am Coll Cardiol 2002; 40: 780-788.

13 Dimopoulos K, Inuzuka R, Goletto S, et al. Improved survival among patients with Eisenmenger syndrome receiving advanced therapy for pulmonary arterial hypertension. Circulation 2010; 121: 20-25.

14 Condliffe R, Kiely DG, Peacock AJ, et al. Connective tissue diseaseassociated pulmonary arterial hypertension in the modern treatment era. Am J Respir Crit Care Med 2009; 179: 151-157.

15 Galie N, Manes A, Negro L, et al. A meta-analysis of randomized controlled trials in pulmonary arterial hypertension. Eur Heart J 2009; 30: 394-403.

16 Ware JE, Sherbourne CD. The MOS 36-item short-form health survey (SF-36): conceptual framework and item selection. Med Care 1992; 30: 473-483.

17 Rector TS, Kubo SH, Cohn JN. Patients' self-assessment of their congestive heart failure: part 2 . Content, reliability and validity of a new measure: the Minnesota Living with Heart Failure Questionnaire. Heart Failure 1987; 1: 198-209.

18 Pepke-Zaba J, Gilbert C, Collings L, et al. Sildenafil improves health-related quality of life in patients with pulmonary arterial hypertension. Chest 2008; 133: 183-189.

19 Pepke-Zaba J, Beardsworth A, Chan M, et al. Tadalafil therapy and health-related quality of life in pulmonary arterial hypertension. Curr Med Res Opin 2009; 25: 2479-2485.

20 Barst RJ, McGoon M, McLaughlin V, et al. Beraprost therapy for pulmonary arterial hypertension. J Am Coll Cardiol 2003; 41: 2119-2125.

21 Shafazand S, Goldstein MK, Doyle RL, et al. Health-related quality of life in patients with pulmonary arterial hypertension. Chest 2004; 126: 1452-1459.

22 Taichman DB, Shin J, Hud L, et al. Health-related quality of life in patients with pulmonary arterial hypertension. Respir Res 2005; 6: 92.

23 Cenedese E, Speich R, Dorschner L, et al. Measurement of quality of life in pulmonary hypertension and its significance. Eur Respir $J$ 2006; 28: 808-815.

24 Chua R, Keogh AM, Byth $\mathrm{K}$, et al. Comparison and validation of three measures of quality of life in patients with pulmonary hypertension. Intern Med J 2006; 36: 705-710.

25 Zlupko M, Harhay MO, Gallop R, et al. Evaluation of diseasespecific health-related quality of life in patients with pulmonary arterial hypertension. Respir Med 2008; 102: 1431-1438.

26 McKenna SP, Doughty N, Meads DM, et al. The Cambridge Pulmonary Hypertension Outcome Review (CAMPHOR): a measure of health-related quality of life and quality of life for patients with pulmonary hypertension. Qual Life Res 2006; 15: 103-115.

27 Gomberg-Maitland M, Thenappan T, Rizvi K, et al. United States validation of the Cambridge Pulmonary Hypertension Outcome Review (CAMPHOR). J Heart Lung Transplant 2008; 27: 124-130.

28 Meads DM, McKenna SP, Doughty N, et al. The responsiveness and validity of the CAMPHOR Utility Index. Eur Respir J 2008; 32: 1513-1519.

29 Chen H, De Marco T, Kobashigawa EA, et al. Comparison of cardiac and pulmonary-specific quality-of-life measures in pulmonary arterial hypertension. Eur Respir J 2011; 38: 608-616.

30 Quirk FH, Jones PW. Repeatability of two new short airways questionnaires. Thorax 1994; 49: 1075P. 